\section{Community hospitals}

\section{Many provide acute services}

EDrror,-Sam Ramaiah raises several relevant issues relating to community hospitals today. ${ }^{1}$ The experience he reports from South Tees, however, focuses only on the non-acute aspects of care in such hospitals. His vision of an administrative centre with little acute medical activity is far removed from reality.

Many community hospitals are already adapting to meet the challenges of providing acute care. Day surgery and minimal access techniques are expanding the range of surgical activity currently suitable for such hospitals. The introduction of ultrasound imaging, gastrointestinal endoscopy, and desk top laboratories has greatly enhanced locality diagnostic services.

In the present climate in the NHS, specialists are increasingly aware of patients' preference to be seen and treated in their own community and of general practitioners' preference for this. The planned development of community based services with a $40 \%$ reduction in beds in district general hospitals; a considerable increase in locality based outpatient clinics; and the increase in the number of over 85 year olds, in whom care and not cure is practical, are likely to lead to an increased demand for beds in community hospitals.

Each community hospital continues to evolve uniquely to meet local needs and in today's competitive setting can still do so successfully. The identification and development of appropriate services are vital. Innovations in local care are legion, and several will be featured in the annual symposium of the Community Hospitals Association to be held in Hythe on 3-4 May. Those who doubt, or lack ideas, should book now.

DAVID POPE

Quarter Jack Surgery,

Dorset BH21 1AP

1 Romaiah S. Community hospitals in the new NHS. $B M \mathscr{F}$ 1994;308:487-8. (19 February.)

\section{Community hospitals not available to everyone}

EDrroR,-Small hospitals come into and go out of fashion, as Sam Ramaiah says.' They have been described as cottage hospitals, general practitioner hospitals, community hospitals, and community care centres. One issue that is often overlooked is the equity of care that they provide. For some services (such as outpatient and casualty services) they may improve equity by bringing services to rural areas. But for other services such as general practitioner beds (particularly in urban community hospitals) inequity will arise if only a proportion of general practitioners have access to these beds. In practice (and leaving aside the problem that some general practitioners may not want to use community hospital beds) this seems inevitable since most small community hospitals can cover the patients of only 15 to 20 general practitioners. ${ }^{2}$ In most districts it is inconceivable that enough community hospitals could be built to serve all patients.

One solution suggested in 1974 was to build larger community hospitals or to convert other hospitals into community hospitals. ${ }^{3}$ The concept was unpopular, and few units conformed to this plan. ${ }^{2}$ The idea has resurfaced ${ }^{5}$ but may founder again if in some areas district general hospitals are downgraded to community hospitals, which is likely to cause considerable public opposition. Another reason for the lack of large community hospitals is that their small size is seen by many as a strength.

Another solution is to consider some of the "rival" institutions described by Ramaiah as complementary to community hospitals rather than a threat. They may be used to provide services in areas where there is no community hospital cover. In Buckinghamshire, where there are five community hospitals covering half the population, we have been working closely with the social services department, which is developing its network of "resource centres" (part III homes with an extended and more flexible role). We hope to agree joint policies for certain services such as respite care to improve equity of access across the county.

Department of Public Health Medicine,

DAVID CHAPPEI

Milton Keynes Hospital Campus,

Milton Keynes MK6 5LD

1 Ramaiah S. Community hospitals in the new NHS. $B M$ 1994;308:487-8. (18 February.)

2 Tucker $\mathrm{H}$. The role and function of community hospitals. London: King's Fund, 1987. (Project paper 70.)

3 Department of Health and Social Security. Community hospitals. their role and development in the National Health Service. London: HMSO, 1974.

4 Dixon PN, Gatherer A, Pollock RM. Hospital services for the 21st century. Oxford: Oxford Regional Health Authority, 1992.

5 Welsh Health Planning Forum. Health and social care 2000: framework for services. Cardiff: WHPF, 1992.

\section{No one asked the patient}

EdrToR,-I read M Heim and colleagues' debate on a difficult case with concern. Several doctors were asked how best to manage a 68 year old diabetic woman with a right below knee amputation and an infected ulcer on her left heel who presented with a fracture of her left hip. There were two schools of thought-to operate and not to operate-each of which had risks and benefits. Members of each school argued their case forcefully.

But no one asked the patient what she wanted. Surely in such cases of finely balanced clinical judgment it is the patient who, after the situation has been explained, should take the final, difficult decision. After all, the decision is more to do with the balance between risk and return than with medical knowledge. The job of doctors in such situations is to present unbiased advice and not to take decisions, based on their own values, on the patient's behalf. As well as being the right action for the patient this is the best option for the doctor. Who among us needs another difficult value based judgment?

London NW3 4S

SUSAN DICKIE

1 Heim $M$, Zievner Y, Nadorvna H, Azaria M, Ruckley CV, Klenerman L, et al. Should an elderly diabetic woman with right below knee amputation and an infected sore on her left heel be operated on for a fractured hip? BMf 1994;308:517-9. (19 February.)

\section{Mental health law}

EDITOR,-We were interested to read Nigel Eastman's comments on the possible lack of knowledge of mental health law among doctors' ${ }^{1}$ and to learn that the Royal College of Psychiatrists and the Department of Health are considering action to remedy the situation. ${ }^{2}$ The problem is not confined to a single jurisdiction. Recent work in Scotland has shown that junior psychiatrists at all stages of training have a patchy knowledge of the provision made in the Mental Health (Scotland) Act 1984 for emergency compulsory detention ${ }^{3}$ and that the same is true of general practitioners (M S Humphreys and A Ryman, unpublished data). This is obviously of concern in a country where the most common means of formal admission to hospital-in more than 3000 cases each year and for up to 72 hours at a time-is an "emergency recommendation." This may be made by any registered medical practitioner acting alone with, "where practicable," the consent of a relative or specially trained social worker. The need for the continuing education of clinicians has been recognised, and, in collaboration with the Mental Welfare Commission for Scotland, we are producing an educational package for doctors who use the emergency powers of the act.

Further research into doctors' understanding and practice of the law in this and other areas is clearly needed. In our opinion, the problem is not just that doctors are ignorant of the facts. Ease of access to a process and superficial familiarity with it may lead to complacency. Important issues of civil liberties may be taken less seriously than they should be. A survey of psychiatrists working in the United States found that the rather dismissive and paternalistic attitudes adopted by participating practitioners towards the use of involuntary admission to hospital was of equal, if not greater, concern than their apparent lack of familiarity with the law. ${ }^{4}$

Until there is a more pervasive sense of concern for mentally disordered people it may prove difficult to effect change even among professionals. There are still those who might be prepared to condone the use of mental health legislation as an instrument of social control..$^{5}$ We trust that they are in the minority.

MARTIN S HUMPHREYS JOHN R GEDDES

Royal Edinburgh Hospital,

Edinburgh EH10 5HF

1 Eastman N. Mental health law: civil liberties and the principle of reciprocity. BMf 1994;308:43-5. (1 January.)

2 Caldicott F, Mann S. Mental health law. BMf 1994;308:408-9. (5 February.)

3 Humphreys MS. Junior psychiatrists and emergency compulsory detention in Scotland. Int $f$ Law Psychiatry (in press).

4 Affeck GG, Peske MA, Wintrob RM. Psychiatrists' familiarity with legal statutes governing emergency involuntary hospitali-
(affect sation. Am f Psychiatry 1978; 135:205-9.

5 Matheson IC, Leverton MJ, Patchett PA. Mental health law. $B M F$ 1994;308:409. (5 February.)

\section{Acute renal failure associated with NSAIDs}

EDITOR, - G W Smith and S B Cohen report on a 79 year old woman who was taking non-steroidal anti-inflammatory drugs and developed renal impairment and hyperkalaemia when a urinary tract infection was treated with trimethoprim.' They unreasonably dismiss the non-steroidal anti-inflammatory drug as a possible cause of the renal disease.

Non-steroidal anti-inflammatory drugs inhibit the normal tonic renal vasodilatation induced by prostaglandin. Loss of this tonic dilatation may be tolerated during health but not in unwell patients, particularly if there is volume depletion or a strong vasoconstrictive drive. ${ }^{2}$ Many illnesses, including urinary tract infection, can result in enhanced renal vasoconstriction mediated particularly by the renin-angiotensin axis. In the absence of drugs these renal effects of angiotensin II are opposed by prostaglandins. ${ }^{3}$ Acute salt or volume depletion is sufficient to render even young health volunteers at risk of renal impairment induced by non-steroidal anti-inflammatory drugs, ${ }^{2}$ and elderly people seem particularly susceptible to these effects. ${ }^{4}$

Thus an elderly patient who is well may have stable renal function while taking non-steroidal anti-inflammatory drugs; illness, however, may result in enhanced vasoconstriction which cannot be opposed by prostaglandins in the kidney and therefore results in a fall in the glomerular filtration rate. Hyperkalaemia is often severe and is a well recognised effect of non-steroidal antiinflammatory drugs when renal function becomes impaired. ${ }^{2}$

The timing of the renal impairment in the case reported fits with that of the urinary tract infection (which was severe enough to merit admission to hospital) and its effect on a kidney deprived of 